\title{
Congenital Peribronchial Myofibroblastic Tumor
}

National Cancer Institute

\section{Source}

National Cancer Institute. Congenital Peribronchial Myofibroblastic Tumor. NCI

Thesaurus. Code C142823.

A rare lung neoplasm that occurs in the intrauterine and perinatal period. It is characterized by the proliferation of spindle cells in an interstitial, peribronchial pattern. Surgical resection of the involved lung parenchyma is the treatment of choice. 